\title{
Study on the Creative Design of Cultural Landscape in Urban
}

\author{
Landscape \\ Xiao Qianwen \\ Hubei University of Technology \\ Lizhi Road Hongshan District Wuhan, Hubei Province
}

Abstract - Under the background of globalization, the design of cultural landscape can not only represents the common concepts and ideas of the whole urban landscape design but also has unique cultural elements. The space design, design techniques, unaffected logic thinking and natural aesthetic characters all provide unique Chinese cultural elements for the creative design of modern cultural landscape. How to creatively refine and adopt the Chinese traditional culture under the basis of inheritance and understanding and involve the cultural elements into the urban landscape design and make the urban landscape design full of ecology and humanistic beauty with the cultural elements of classic garden so as to realize the unification of Chinese humanistic elements can humanistic care are the topic that worth our attention as well as the problems in the modern urban landscape design that are urgent to be solved.

Key words-cultural landscape; creative design; classical garden; Chinese humanistic elements

\section{INTRODUCTION}

The creative design for humanistic elements can be called the soul of urban landscape design and can reflect the historical and regional cultural relics, cultural customs, aesthetic characters and cultural values, which all can affect the aesthetics and values of human beings by the humanistic elements in landscape design. The skillful combination of ecological landscape design and humanistic elements can enhance the attractions of urban landscape. The humanistic elements consist of material cultural and non-material cultural elements, which is the history and cultural relics left behind with the essence of thousands of years' human history and are full of continuity. China is a nation of five thousand years history. All are the wisdom of human beings, including material cultures such as the ancient architecture, tombs, old residence, classical gardens and the non-materials cultures such as myths and tales, folk customs, national customs; and all of these are also the valuable wealth for the creative design of cultural landscape during the design of urban landscape design.

Chinese humanistic elements refer to the de-westernization in the design of urban landscape design and emphasis on the native cultures of China, which not only represents the traditional culture but not to decorate westernized space with classic elements. It lies in the Chinese traditional culture and cultural property is its essential feature. Chinese cultural elements are full of glamour and wide contents so as to reflect the pursuit of beauty by human 
beings; Chinese give much more emphasis on the inheritance of excellent traditions so as to re-absorb and refine the Chinese humanistic elements and make the urban landscape design elements full of fashionable feature. For example, materials with Chinese cultural elements are widely used in the urban landscape design; bricks, woods, metals and stones etc. can be changed to bronze telephone booth, wooden chairs which echo with the surrounding scenery by bold creation, and makes them refreshing to urban citizens. Chinese humanistic elements are with great advantages in spirits. Under the present background of globalization, it is very important for the urban landscape design to emphasize the Chinese humanistic elements. Chinese humanistic elements can involve Chinese traditional national spirits into the cultural landscape design and involve Chinese history and culture into the modern development as well as spread Chinese historical invention and splendid culture with unique characteristics to the world.

The urban landscape design firstly emphasize the relation of human and ecology which can make the human organic body harmony with the surrounding natural environment so as to realize the sustainable ecological civilization. Secondly, creation should replace imitation and deprive of the monotonous of all. The wholly westernization is lack of humanistic element and lack of the national and regional cultural essence. It can make use of the Chinese humanistic elements to make the urban landscape design unique and arouse the echoes of residence. In a word, the design of urban landscape should not only emphasize the harmony of ecological system as well as human and nature but also the application of native humanistic elements. With Chinese humanistic elements and the supplementary of western culture, it can realize the harmony of heaven, earth and human beings as well as harmony of landscape, ecology and humanity.

\section{Features of the humanistic elements in Chinese classical gardens}

Gropius once said "The concept of beauty changes with the advancement of ideas and technology. When people find the eternity beauty, they fall into imitation and stasis. We can no longer restless vintage. Architecture would die without advancement." Therefore, the application of Chinese humanistic elements in urban landscape design is not lockstep or copying, but instead it is to break the psychological stereotype of designers under the basis of understanding traditions cultures and regional cultures and to re-appear the glamour of Chinese traditional cultures by divergent thinking and creative thinking. By using special design methods, it can refine the Chinese cultural elements and create typical Chinese images from the spiritual layers of Chinese cultural elements and develop people's rich imagination and confer the urban landscape design with higher spiritual realm.

Chinese classical garden realize the harmony of natural beauty and architecture beauty and is full of the rich poetry and painting flavor. It relies on nature and is superior to nature and is full of high achievement and referential values from architecture aspects and landscape design aspects. Much contemporary urban landscape design adopts the techniques and elements of Chinese classical gardens and it can find the traces of space design, space division method, pavilions styles as well as the handling of waters etc. However, most urban landscape design only imitates the appearance of Chinese classical gardens and only pays attention to the methods, spaces and materials of classical 
gardens instead of images and ideas.

The Chinese cultural elements in the urban landscape design of Chinese classical gardens should be refined from traditional ideas and cultures. By trying the Chinese ancient unaffected logic, methods and aesthetic standards, it can make the humanistic creations in urban landscape design so as to find out the elements that is suitable to the modern urban life style and aesthetic features.

\section{Reserved and refined sentiment and infinite connotations}

Traditional Chinese art emphasizes reserved thoughts. Therefore, Chinese classical gardens cannot be seen through after entering into the gardens. It sets up firstly with artificial hills and zigzag corridors etc. so that tourists can travel through it with new views everywhere and have the feeling of " when there seems no way out, there are numerous mountains and waters as well as villages in front". Tourists can not feel the boundary of gardens and have endless surprises in the landscape design which makes the landscape design full of glamour.

\section{Make use of the local conditions and adjust landscape with landscapes}

Chinese ancient garden often makes use of empty corridors and pavilions to embrace beautiful landscape into the garden. By making use of limited geographical locations, it combines the landscape inside the gardens and outside the gardens. For example, the echo of weeping willows in Lac de Kunming and the mountains in Longevity Mountain makes use of the splendid landscape design concept and combines the landscape together.

Chinese classical gardens cannot only make use of the local conditions from macro aspects but also in micro aspects, such as the garden walls, plants, animals and geometry windows with national features carved on the corridor walls from which tourists can savor the beautiful landscape in the garden with different taste. Socrates once said "art is to properly arrange everything and make this part harmony with other parts until it can make a regular and orderly whole". Therefore, the two ideas of humanistic ideas mentioned above in the classical garden design can be applied in the creative design of cultural landscape in the modern urban landscape design so as to present the national culture cultivations and humanistic elements.

\section{The humanistic elements of the classical gardens in the urban landscape design}

City is an important carrier of historical development. Each city has the inheritance of historical development and culture, which becomes important culture and historical stations with unique regional features. However, Chinese modern urban landscape design locates mainly in the center of square and divides the square by linear roads into square districts. By placing decorative plants on both sides, the whole landscape design is orderly but is dull with no unique features, which lacks the endless meaning and vivid features of Chinese classical gardens. Therefore, urban landscape design requires re-creation but also requires maintaining the original historical cultures to some extent. Urban landscape design without humanistic elements is of no soul, no taste and no spirits. Urban landscape design is to inherit and develop traditional culture but also to seek for harmony and creative invention, among which refining Chinese humanistic elements from classical landscape design for humanistic landscape design creation is very important and unique. 
By using the humanistic elements of classical gardens in the urban cultural landscape, the following aspects can be creatively designed:

1. The humanistic landscape design reflects the Chinese traditional culture intention. The cultural landscape design in modern urban landscape can consult the micro landscape-creation methods of classical gardens and represents the Chinese atmosphere by decorations such as roads, walls etc. For example, by involving the Chinese red image in urban landscape, it can not only make the urban landscape vivid but also make people feel the intensive Chinese taste. It can use of the Chinese traditional paper-cutting art to paint or carve the decorative image; it can also Chinese Zodiac for landscape decorative design or painting design to show traditional Chinese culture. Besides, it can also use modern sculpture to create Chinese folk game or cultural recreations, such as diabolo, rope-skipping and other cultural landscape with unique Chinese characteristics, which can stimulate ones' attention and recall ones' memory and also make the humanistic landscape design full of Chinese cultural elements. The Tianjing ancient culture street's pavement with the abstract symbol of coins is one of the representatives of using humanistic elements by Chinese, which not only decorates the road but also with Chinese cultural elements.

2. The space design should create landscape with multiple layers. The space traveling orders of urban landscape should consult the methods of classical gardens by the process of "starting-guiding-peak-end". The design of urban landscape should not be seen through at once but should display new landscape with the changes of road and views. Dividing the landscape space with different roads or types in the landscape design can create the sense the transference between landscape and space, which can harvest different views and feeling with limited landscape.

3. Diverse landscape-making methods. Modern urban cultural landscape design should consult the unique aesthetic methods of Chinese classical gardens. For example, make landscape similar to lakes by using mirrors so as to make projection of mountains, buildings, landmarks. The landscape is refined and delicate and with styles of endless meanings of Chinese classical gardens. The flowers, woods, mountains, stones, sculptures all need the landscape-making methods of classical gardens to form multiple layers urban landscape with Chinese humanistic elements.

\section{Conclusion}

Under the background of globalization of today, urban landscape design should realize the harmony of ecology and human beings as well as the humanistic elements and humanistic care, which should consult the western concepts of urban landscape design but also maintain the regions and nationality cultural features. The humanistic element of Chinese traditional culture, especially the Chinese humanistic elements in the classical gardens which represent the traditional ideas and aesthetic features, has something worth our digging and creatively application, which is also the objective requirement of Chinese humanistic elements in the urban landscape design.

\section{Acknowledgement}

Project: Human Studies and Social Science Research Plan of Education Bureau

Project No.: 15YJA760035 


\section{References}

[1] $\mathrm{Hu}$ Ying. Influence of regional culture on landscape design--Taking Summer Palace in Beijing as an example [J].Popular Literature,2015.

[2] Chang Heling. On the influence of Chinese traditional culture on garden design $[\mathrm{J}]$.Art
Circle,2012.02.

[3] Zhu Lijun. Study on the methods of new Chinese garden landscape design [J].Database of Chinese Excellent Master Dissertation,2012.04. 